\title{
Paleoethnobotany and Ancient Alcohol Production: A Mini-Review
}

\author{
Matthew E. Biwer ${ }^{1^{*}}$ and Amber M. VanDerwarker ${ }^{1}$ \\ Author addresses: ${ }^{1}$ Department of Anthropology, University of California, Santa Barbara, CA 93106-3210, USA. \\ ${ }^{*}$ Corresponding author: mbiwer@umail.ucsb.edu
}

Received: March 18, 2015

Volume: 6(1):28-31

Published: May 5, 2015

(C) 2015 Society of Ethnobiology

\begin{abstract}
The production and consumption of alcoholic beverages in the past is an important consideration when addressing issues involving ancient food. However, successfully demonstrating that alcoholic beverages were produced in prehistoric contexts is problematic. As a result, archaeobotanists have developed a multi-scalar approach, incorporating multiple lines of evidence, to argue for the production of fermented beverages in the past.
\end{abstract}

Keywords: paleoethnobotany, archaeology, fermented beverages

The cultural practices surrounding the production and consumption of alcoholic beverages represent a growing area of archaeobotanical inquiry. As a food, alcohol is of great importance to many cultures around the world and is of interest to researchers studying myriad issues, including gender, religion, identity, politics, status, labor, and economy (Dietler 2006; Jennings and Bowser 2009; McGovern 2009; Smith 2008). However, it can be problematic to convincingly argue for the production of alcohol in the past using archaeological evidence. How can archaeologists demonstrate that ancient plants were used for making alcohol and not for some other purpose? To address this question, archaeobotanists have adopted a multi-scalar approach that incorporates several lines of evidence to address issues related to the production and cultural role(s) of alcoholic beverages in the past. These lines of evidencemacrobotanical (seeds, wood charcoal) and microbotanical $^{1}$ (pollen, starch grains, phytoliths) remains, spatial contexts of plant use and discard, documentation of ethnohistoric practices, and the correspondence between plant ingredients and other artifactscan be integrated to identify ancient production areas of fermented beverages.

Humans have been making alcohol for at least 10,000 years and have developed a variety of methods to produce it. Generally, alcohol is produced when yeast converts plant starches and sugars into ethanol (alcohol) during the process known as fermentation. Grains, tubers, roots, and fruits are commonly used to produce alcohol because they possess a readily available source of starches and sugars, though other ingredients (i.e. honey) can also be used. There are a number of preparation steps that can be involved in alcohol production, including steeping, sprouting, pressing, mashing, drying, toasting, grinding, boiling, and distilling plant parts for a range of effects. There is also a wide range of botanical additives, including spices and herbs, which are used to boost flavor and aroma.

Because the beverage itself is unlikely to preserve in the archaeological record, archaeobotanists must infer ancient alcohol production by examining the structure and form of recovered seeds and examining the spatial context of recovery. For example, the process of malting, which involves soaking and sprouting grains in water to convert starches to sugar for fermentation, alters the form of the grain from its original state, which can be seen archaeologically. Bouby et al. (2011) provide archaeobotanical evidence for malted barley (Hordeum vulgare Linnaeus Poaceae) in the Mediterranean region of France during the $5^{\text {th }}$ century A.D. In their analysis of a single household context, the authors find a high density and ubiquity of barley (compared to other taxa recovered from a single household); moreover, $90 \%$ of these barley seeds show a similar state of induced germination. This evidence for germination, in addition to the lack of weedy species in the assemblage, suggests the grain was intentionally processed to remove unwanted taxa and then soaked to begin the process of fermentation. Additionally, other artifactual data, including fermenting pots, ovens, grindstones, and areas to dry the sprouted grain-essentially, a beer-making toolkitwere also recovered from the household, lending further support to Bouby et al.'s (2011) hypothesis. 


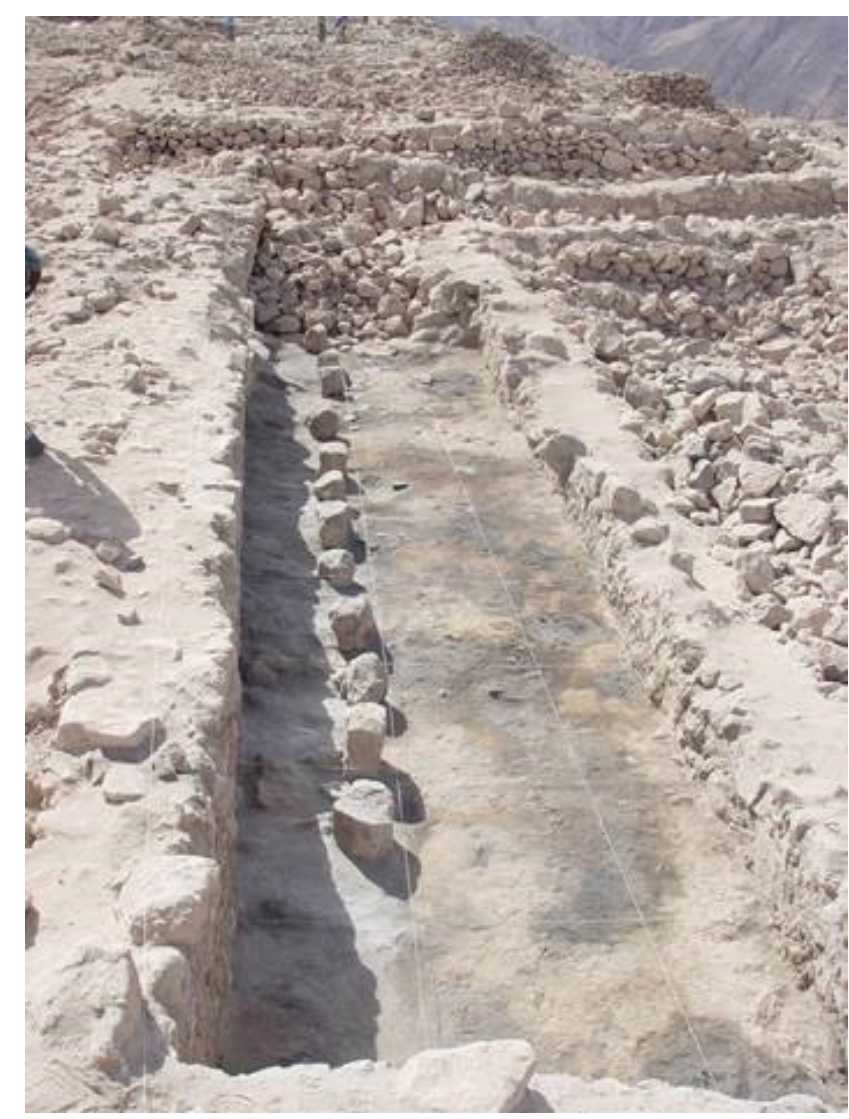

Figure 1. The boiling room of the Brewery excavated on the top of Cerro Baúl, Moquegua, Peru (photo courtesy of Patrick Ryan Williams).

A similar technique of documenting changes in seeds as a result of the alcohol production has been used in the Peruvian Andes. Archaeobotanists have found that when the drupes of the Peruvian Pepper Tree (Schinus molle Linnaeus Anacardiaceae), the key ingredient used in making the alcoholic beverage chicha de molle, are steeped and boiled in water prior to fermentation, they take on an irregular form that is distinct from the non-boiled globular fruit (Sayre et al. 2012:236). Similarly, in Southern France the association of domesticated grape (Vitis vinifera Linnaeus Vitaceae) seeds with crushed grape skins, pedicels, and rachis indicate that these grapes were not simply cooked at the site, but that the fruits were pressed prior to fermentation to extract the juice for wine production (Figueiral et al. 2010). Thus, the state of recovered seeds in both cases suggests brewing and fermentation took place, and also provides a means to evaluate the steps of each brewing process.

In addition to the morphology of macrobotanical remains (e.g., evidence of sprouting, boiling, pressing), the association of macrobotanical remains with brewing contexts (i.e., the presence of large cooking and/or fermentation containers, grinding stones, cooking fires, lack of diversity in activities in the space, etc.) provides clues to which plants were used to produce alcohol and how they were processed prior to boiling and fermentation. In the Moquegua Valley of Southern Peru, archaeologists identified an ancient Wari (A.D. 600-1000) brewery on the summit of Cerro Baúl, a provincial administrative center of the Wari Empire (Moseley et al. 2005). This trapezoidal structure contains three separate rooms, each of which was identified as a distinct area for milling, boiling, and fermentation, respectively (Figure 1). Other evidence that supports the interpretation that this space was a specialized chicha beer production area includes: the presence of grinding slabs in the milling room, the remnants of large boiling/fermentation ceramic vats with a line of hearths lined paralleling the wall, the presence of stone pedestals used to support the vats in the boiling room, and the remains of drinking cups (keros) recovered throughout the structure. In addition, the recovery of thousands of boiled, desiccated, and carbonized Schinus molle drupes, alongside carbonized maize (Zea mays Linnaeus Poaceae) kernels and embryos (another ingredient in chicha production), suggests the brewers were steeping the molle fruits and grinding sprouted maize as part of the production process involved in making chicha (Goldstein et al. 2009).

Microbotanical data have also been used to identify and document the production of fermented beverages. In particular, evidence from starch grains and phytoliths has been used to test the sugar stalk hypothesis put forth by Smalley and Blake (2003). These authors suggest early Mesoamerican maize was initially cultivated not for its grain but rather for its stalk, which the authors argue would have been valued for its sugary pith, an attractive resource for the production of alcohol. Piperno et al. (2009) recently tested this hypothesis by extracting and identifying phytoliths and starch grains from chipped stone tools and grinding stones recovered from an Archaic-period ( 7000 B.C.) site of Xihuatoltla, located in the Central Balsas River Valley of Mexico; this location is significant as it has recently been identified as the origin of maize domestication in addition to being the home of maize's wild ancestor, teosinte (Zea mays ssp. Parviglumis Iltis \& Doebley Poaceae) (Buckler et al. 2006; Fukunaga et al. 2005; Matsuoka et al. 2002). The results of analysis conducted by Piperno and colleagues indicate: a lack of teosinte starch grains and 
phytoliths; the presence of starch grains and phytoliths from domesticated maize kernels; and no evidence of phytoliths or starch grains from the stalks of maize or teosinte (Piperno et al. 2009:5020-5022). Thus, the currently available microbotanical data from maize's center of origin does not support Smalley and Blakes (2003) hypothesis that the grain was initially exploited for its sugary stalk to produce alcohol.

Another microbotanical study regarding maize fermentation uses phytoliths to assess the emergent role of domesticated maize (Zea mays Linnaeus Poaceae) in Formative-period ( $\sim 800$ B.C.) foodways of the Titicaca Basin in the South American Andes (Logan et al. 2012). The authors use a combination of phytolith data recovered from human teeth, ritual paraphernalia, ceramic pots, lithic tools, and contextual analysis of space (e.g., areas identified as public ritual spaces versus household contexts of daily food production) to assess the early uses of beer in the region. Their results indicate a lack of phytoliths from the interiors of domestic cooking vessels, suggesting maize was not boiled or cooked as part of daily subsistence. Instead, it appears that maize played a larger role in ceremonial and ritual activities, as indicated by the identification of maize glume and kernel phytoliths on: (1) grinding stones recovered near ceremonial spaces; (2) ritual paraphernalia, such as incense burners (incensarios); and (3) the teeth of human sacrifice victims recovered from ritual locations (Logan et al. 2012:247-248). Considering the phytolith evidence and spatial contexts in tandem, the authors argue that the earliest use of maize in the Titicaca Basin is most likely attributable to the production of chicha de main for consumption during ritual activities, rather than production for daily household consumption.

We emphasize a multi-proxy approach to research on alcohol production because of the limitations inherent in using organic remains. Relying primarily on paleoethnobotanical data to address the ancient production of alcoholic beverages is problematic because of the nature of plant preservation. How can archaeologists who work in areas with minimal or no botanic preservation find evidence for the production of fermented beverages? The presence and contexts of materials used to produce alcohol (hearths, grinding stones, ceramic vessels for boiling, fermenting, and storing of liquids) can be taken together with ethnographic evidence to assess whether or not alcohol could have been produced at a site. While archaeobotanical materials are useful for identifying the kinds of fermented beverages produced at the site, the spatial associations and contexts of production-related materials allow us to address the actual production process that ancient peoples used to ferment beverages.

Research focusing on the production of fermented beverages and their cultural significance in the past represents a small, but growing, area of paleoethnobotany. Methodological developments in archaeobotany, in particular the analysis of phytoliths and starch grains, have been critical in advancing interpretive power, especially in very early production contexts in which the preservation of macrobotanical remains is poor (e.g., the Balsas River Valley case). By combining archaeobotanical data with artifactual data and information on the social/spatial contexts of use, archaeobotanists can continue to develop new ways to better conceptualize the production and consumption of alcoholic beverages in the past.

\section{References Cited}

Buckler, E. S., M. M. Goodman, T. P. Holtsford, J. F. Doebley, and G. J. Sánchez. 2006. Phylogeography of the Wild Subspecies of Zea mays. Maydica 51:123134.

Bouby, L., P. Boissinot, and P. Marinval. 2011. Never Mind the Bottle: Archaeobotanical Evidence of Beer -brewing in Mediterranean France and the Consumption of Alcoholic Beverages During $5^{\text {th }}$ Century B.C. Human Ecology 39:351-360.

Dietler, M. 2006. Alcohol: Anthropological/ Archaeological Perspectives. Annual Review of Anthropology 35:229-249.

Figueiral, I, L. Bouby, L. Buffat, H. Petitot, and J. F. Terral. 2010. Archaeobotany, Wine Growing and Wine Producing in Roman Southern France: The Site of Gasquinoy (Beziers, Herault). Journal of Archaeological Science 37:139-149.

Fukunaga, K., J. Hill, Y. Vigouroux, Y. Matsuoka, J. Sánchez, K. Liu, E. S. Buckler, and J. Doebley. 2005. Genetic Diversity and Population Structure of Teocinte. Genetics 169:2241-2254.

Logan, A. L., C. A. Hastorf, and D. M. Pearsall. 2012. "Let's Drink Together": Early Ceremonial Use of Maize in the Titicaca Basin. Latin American Antiquity 23:235-258. 
Goldstein, D. J., R. C. Coleman Goldstein, and P. R. Williams. 2009. You Are What You Drink: A Sociocultural Reconstruction of Pre-Hispanic Fermented Beverage Use at Cerro Baul, Moquegua, Peru. In Drink, Power, and Society in the Andes, edited by Justin Jennings and Brenda Bowser, pp. 133-176. University of Florida Press, Gainesville, FL.

Jennings, J., and B. Bowser. 2009. Drink, Power, and Society in the Andes: An Introduction. In Drink, Power, and Society in the Andes, edited by Justin Jennings and Brenda Bowser, pp. 1-27. University Press of Florida, Gainesville, FL.

Matsuoka, Y., Y. Vigouroux, M. M. Goodman, G. J. Sánchez, E. Buckler, and J. Doebley. 2002. A Single Domestication for Maize, shown by Multilocus Microsatellite Genotyping. PNAS 99:6080-6084.

McGovern, P. E. 2009. Uncorking the Past: The Quest for Wine, Beer, and other Alcoholic Beverage. University of California Press, Los Angeles, CA.

Moseley, M. E., D. J. Nash, P. R. Williams, S. deFrance, A. Miranda, and M. Ruales. 2005. Burning Down the Brewery: Establishing and Evacuating an Ancient Imperial Colony at Cerro Baúl, Peru. PNAS 102:17264-17271.
Piperno, D. R., A. J. Ramere, I. Holst, J. Iriarte, and R. Dickau. 2009. Starch Grain and Phytolith Evidence for Early Ninth Millennium B.P. Maize from the Central Balsas River Valley, Mexico. PNAS 106:5019-5024.

Sayre, M., D. Goldstein, W. Whitehead, and P. R. Williams. 2012. A Marked Preference: Chicha de Molle and Huari State Consumption Practices. Nawpa Pacha 32:231-282.

Smith, F. H. 2008. The Archaeology of Alcohol and Drinking. University Press of Florida, Gainesville, FL.

\section{Biosketches}

Matthew E Biwer is a Ph.D student in the Department of Anthropology at the University of California, Santa Barbara. His work focuses on paleoethnobotany, culture contact, and foodways in the Peruvian Andes.

Amber M. VanDerwarker is an Associate Professor of Anthropology at the University of California, Santa Barbara. She has been involved in field and laboratory work in Mexico, Eastern North America, and Peru.

\section{Notes}

${ }^{1}$ This review does not include those studies of chemical residue analysis of archaeological materials. 